\title{
University Professors' Perceptions About Patient Safety Teaching in an Interprofessional Education Experience: A Phenomenological Study
}

Gabriele Carlomagno Vilanova, MSc, PhD student

Florence Nightingale Faculty of Nursing and Midwifery, King's College, London, England

(iD https://orcid.org/o0oo-0002-6222-8284

Andreas Xyrichis, $\mathrm{PhD}$

Florence Nightingale Faculty of Nursing and Midwifery, King's College, London, England

(iD) https://orcid.org/0000-0002-2359-4337

Elena Bohomol, $\mathrm{PhD}$

Faculty of Nursing (Escola Paulista de Enfermagem), UNIFESP, São Paulo, Brazil

(iD https://orcid.org/o000-0002-7196-0266

Rosana Aparecida Salvador Rossit, $\mathrm{PhD}$

Centro de Desenvolvimento do Ensino Superior em Saúde (CEDESS), UNIFESP, São Paulo, Brazil. (iD) https://orcid.org/0000-0002-0563-7188

Contact: gabriele.carlomagno@kcl.ac.uk

\section{Abstract}

Background: Interprofessional education (IPE) and patient safety are recurrent and linked themes within the field of healthcare worldwide. International organizations have repeatedly called for and research has shown the benefits of health and social care professionals learning how to work collaboratively and efficiently to provide safer and better care. This study was undertaken to explore professors' perceptions and experiences of an IPE curricula project with a view to improving future patient safety teaching in undergraduate health courses.

Methods: This qualitative study utilized phenomenology as a theoretical framework. The participants were 11 professors from a public university in south-eastern Brazil, recruited through purposeful sampling. Data were collected through semi-structured interviews, which were transcribed and thematically analyzed.

Findings: Four themes were identified: (a) sustaining IPE; (b) stakeholder involvement; (c) pedagogy; and (d) team learning. Enablers to patient safety teaching included the co-location of professors and sharing projects and lectures between them in consonance with the IPE project. Barriers included lack of knowledge of the patient safety national program, inadequate staffing, and significant academic workload.

Conclusion: Professors revealed critical challenges to patient safety teaching within an IPE curriculum. They

Acknowledgment: We are grateful to Iain Ryrie, visiting senior teaching fellow at Florence Nightingale Faculty of Nursing, Midwifery \& Palliative Care, for his suggestions, time, and candid contributions to the final version of this manuscript, and to the three anonymous referees for helpful comments.

Funding acknowledgement: This manuscript was written during the first year of the first author's PhD studies. She is receiving an international scholarship funded by King's College, London. 
perceived patient safety to be an important topic for students but needed more support to integrate the topic into their routine as a formal activity. We call for patient safety policy to be more integrated within the educational system, with the active involvement of professors and other local stakeholders, and for its impact to be evaluated.

Keywords: Interprofessional education; professor; patient safety; curriculum; healthcare.

Date Submitted: July 13, 2020 | Date Published: June 3, 2021

\section{Recommended Citation}

Vilanova, G., Xyrichis, A., Bohomol, E., \& Rossit, R. A. S. (2021). University professors' perceptions about patient safety teaching in an interprofessional education experience: A phenomenological study. Journal of Social, Behavioral, and Health Sciences, 15, 123-140. https://doi.org/10.5590/JSBHS.2021.15.1.10

\section{Introduction}

Interprofessional education (IPE) and patient safety are recurrent and linked themes within the field of healthcare worldwide. International organizations, supported by research evidence, have called for health and social care professionals to learn how to work collaboratively and efficiently to provide safe and better care (Pronovost et al., 2016; World Health Organization [WHO], 2010; Reeves, 2016; Fahs et al., 2017). Growing evidence shows that giving students IPE opportunities to learn how to be active collaborators and communicators is one way to develop safer systems of care and better patient outcomes (Brandt et al., 2014; Reeves et al., 2016a; Reeves et al. 2016b). However, there are challenges in implementing meaningful curricula involving patient safety topics and multiple healthcare professional courses.

In 2009, the WHO launched the "Patient Safety Curriculum Guide for Medical Schools"; and, in 2011, published the "Multi-Professional Patient Safety Curriculum Guide," both of which provide comprehensive advice on how to teach patient safety for all healthcare courses (WHO, 2011). These guides are freely available on the WHO website, with topics designed for a range of students from beginners to experts. Walton et al. (2010) and Farley et al. (2015) analyzed the guides and highlighted their most significant strengthcomprehensiveness. These authors agree that the guides provide universities with an opportunity to develop their patient safety curriculum. However, local adoption of a global framework brings challenges in finding space and time in an over-packed curriculum and depends on university investment and resourcing. Nevertheless, the integration of a worldwide perspective is essential to the development of new ideas, and for finding answers to local problems that enrich existing curricula (Frenk et al., 2010).

Patient safety should form a core part of the education of healthcare professionals (Wu \& Busch, 2019); however, as a scientific discipline, its scope is not settled in all parts of the world beyond its potential to reduce patient harm and preventable deaths (Wears et al., 2016). Little is known about university professors' perspectives and experiences of any facilitators or barriers they might face regarding patient safety teaching within an IPE experience. This study was undertaken to address that gap by exploring professors' perceptions, and experiences of an IPE curricula project, with a view to improving future patient safety teaching in undergraduate health courses.

\section{Background}

More than half a century ago, the WHO published Health for All by the Year 2000 followed by Framework for Action on Interprofessional Education and Collaborative Practice in 2010. These documents outline a strategy to overcome the shortage of resources within the healthcare sector, with global incentives for equitable, safe, and efficient care. International literature shows that IPE and collaborative practice can 
improve patient outcomes and patient safety (WHO, 2010). Moreover, the promotion of interprofessional education facilitates reflections about working in professional silos and can promote more collaborative, effective teamwork. Alongside specific technical skills, interprofessional education develops generic competencies such as the analytical use of both evidence and ethical deliberation in decision-making, shared learning and communication skills, all of which are important for safer care (Frenk et al., 2010).

The WHO frameworks for IPE and patient safety have influenced local policies in different parts of the world. In 2013, the National Patient Safety Program (NPSP) was established in Brazil by the Ministry of Health (Ministério da Saúde (MS) 2013). One of the main objectives of this program was to promote patient safety teaching during undergraduate health courses for both the public and private sectors. It required university professors to include patient safety topics in their classes, lectures, and research projects. Another objective of the NPSP was to establish multi-professional nuclei inside each health service in Brazil (MS, 2013). These nuclei are responsible for risk management, incident report processes, and implementation of safety protocols. The activities performed by safety teams require high levels of interprofessional collaboration to share expertise and teamwork and to coordinate tasks around a common goal of patient safety. The purpose of including safety topics during undergraduate courses is to prepare students for such work before their professional entry into the healthcare system. Consequently, students might be more prepared to work collaboratively and to improve the safety culture inside services. One way to enhance collaborative work with different professionals is to promote IPE initiatives.

The Brazilian Ministry of Health has been promoting initiatives to implement IPE in undergraduate health courses' curricula (Almeida \& Silva, 2019) together with the Pan American Health Organization (PAHO), which operates across North, Central, and South America, and the Caribbean. In July 2019, the Ministry of Education launched a program to promote teaching-service-community integration focusing on the healthcare system in Brazil. This program is called "PET-Health-Interprofessional" and is an attempt to implement IPE within the pedagogical projects of healthcare undergraduate courses (Almeida \& Silva, 2019).

Moreover, healthcare has always been about teamwork, and this necessity has grown in importance because of the evolution of complex healthcare systems. To enhance the chances of more collaborative working practices, IPE involves students of two or more professions learning together. IPE is defined as when "two or more professions learn with, from and about each other to improve collaboration and quality of care" (Centre for the Advancement of Interprofessional Education [CAIPE], 2019). Following the idea that professionals need to work in teams, there is also discussion about the inclusion of patients' involvement as co-producers of their care. IPE pedagogical projects do not focus on healthcare professionals as the central actors within the health system. Rather, they center attention on population needs and how to improve collaborative competencies for professionals to work with the reality and demands of healthcare systems.

Ultimately, there is hope that a curriculum based on effective communication, shared responsibility, and integrated care between different professions can enhance patient safety and decrease the number of preventable errors, mistakes, and deaths. The WHO curriculum is a good starting point for integrating patient safety topics for different healthcare courses, especially in those educational institutions not capable of changing the curricula more broadly. However, some authors have critiqued the oversimplistic way that safety is conceptualized (Lawton, 2018). Sujan et al. (2019) have discussed the pros and cons of conceptualizing safety as the absence of adverse outcomes or as freedom from unacceptable levels of risk. From Hollnagel's (2014) explanation of the different ways that safety is understood, one could argue that the topic is difficult to learn and explain when it is simply defined as the absence of error.

There is enough evidence to conclude that the WHO patient safety curriculum is an important international effort that should not be overlooked by any education institution that plans to include topics for teaching patient safety (Sujan et., 2019). However, a critique of the WHO approach is that it focuses on mistakes and errors as phenomena that can be controlled and detected using risk management, when healthcare and safety 
are much more complex. In this sense, educational institutions that use the WHO framework need to continuously evaluate their safety curriculum to evolve the concept through more complex ways of thinking. The use of systems thinking can provide a more realist approach and has enabled professionals in healthcare to move beyond the old-fashioned "name, blame, and shame" approach (Henriksen et al., 2005). Systems thinking has helped them to understand how different inputs and parts of the system may contribute to failures in the process of care. It becomes possible to focus on "what are the strengths," "what works," and "what is going well" rather than just searching for "what are the weaknesses," "where is the error," and "what is going wrong."

Conceptual and theoretical understandings of IPE are also important to guide evaluations that take account of the complex systems within which it operates. While systems thinking provides a generic framework for understanding the care processes that contribute to a goal of patient safety, Hean et al. (2012 and 2013) present the possible use of theories to construct interprofessional learning best suited to achieving that goal and provide guidelines for how IPE theories can be translated into tangible curriculum opportunities. For instance, social capital theory, adult learning theories, and sociological lenses such as professionalism concepts from Bernstein and Freidson can help professors to succeed with an interprofessional curricula proposal. These ways of thinking do not come naturally; they take time and require new ways of analyzing the context of practice. Although IPE is one way that educational institutions can develop their pedagogical curricula with safety in mind, there are many challenges to better preparing students for the realities of daily working practices. IPE and safety teaching initially require trained professors who are key players since the change will not be possible without their leadership and ownership.

To better understand IPE initiatives for patient safety teaching in Brazil, the authors of this paper explored professors' experiences from a university which has formally presented an IPE pedagogical curriculum since 2006 and follows the national government requirements. The campus is part of a federal and public University in São Paulo state and offers six undergraduate health courses: nutrition, physiotherapy, psychology, occupational therapy, social work, and physical education. The courses are integrated and oriented towards team working and interprofessional collaboration (Batista et al., 2018). Students and professors from all courses work together from the first to the final year in different timetabled sessions. Internationally, preparing staff to deliver interprofessional education is not so common (WHO, 2010). Courses are usually short, and activities are not systematically delivered. However, we chose a setting with experienced IPE professors who have more than a decade of experience promoting IPE daily. Students and professors work together in $80 \%$ of the activities in the first year, $40 \%$ in the second year, $20 \%$ in the third year, and through biweekly meetings in the fourth and fifth years. This paper explores the professors' perceptions of their experiences in the IPE curriculum project with a specific focus on patient safety teaching and learning.

\section{Methods}

\section{Design}

This exploratory qualitative study used phenomenology as a theoretical framework that focuses on individual experiences. Researchers gathered detailed narrative data from the participants' point of view to understand the meaning of an event, a concept, or a phenomenon (Gray, 2014; Creswell \& Creswell, 2017). In this way, the researcher uses an inductive approach to interpret the lived experience's meaning from the participants' description (Gerrish \& Lacey, 2010). Moreover, phenomenology is a philosophical theory, rooted in the work of Husserl, about the way humans experience their consciousness (Smith, 2007). It is interested in how participants express their lived experiences and the interpretations they attribute to them (Parahoo, 2006). 
Phenomenology has an eclectic philosophical tradition which reflects different approaches. For example, transcendental, existential, hermeneutical, linguistic, and other formulations of phenomenology result from Husserl's original work. For the present study, we chose a hermeneutic approach in which the observer is not bias-free and tries to capture the participants' lived experiences by interpretive means. Subsequent reflections on the emergent themes from a set of data contribute to a deeper understanding of the phenomenon of interest. For the current purpose, we wanted to understand how professors experienced patient safety teaching in an interprofessional education pedagogical project.

Hermeneutics does not have a set analytic method (van Manen, 2016), and researchers use different data analysis methods. The purpose of hermeneutic phenomenological research is to bring to light a particular phenomenon and reflect upon the lived meaning of participants' experiences (Goble \& Yin, 2014).

\section{Setting and Participant Recruitment}

The study took place on a single campus of a federal public university in Southeastern Brazil. Professor recruitment was undertaken in two phases, the first of which formed part of a larger quantitative component of a master's degree thesis. The first phase was open to all 140 registered professors who were currently active at the university and whose contact and e-mail information was found on the institution website. Of these, 58 professors declined because they were not familiar with the national patient safety program or were not comfortable talking about the topic. We did not receive a response from 28 , and a further 15 automatic e-mail responses indicated that the professor was on leave. The remaining 39 professors who agreed to participate were initially asked to respond to a questionnaire on the patient safety themes that they covered with students, even if it was not stated in the formal curricula. This helped identify a suitable mixture of participants for the second phase of recruitment, ensuring we captured a range of experiences through indepth interviews. We purposively invited 18 professors during the second phase based on set eligibility criteria: (a) working at the campus since its creation in 2006 and (b) involved with writing curricula or regularly participating in curricula committee meetings. Eleven professors representing six different healthcare undergraduate courses at the university agreed to be interviewed.

\section{Data Collection}

The first author conducted all interviews between January and April of 2017. The interviews were conducted in the Portuguese language, and a Portuguese manuscript was written for this current publication. The manuscript translation was undertaken by the first author and then checked by two senior professors specialized in patient safety and interprofessional education. A third professor was an English language expert who ensured that the translation was accurate. Data on professional background, age, and how long the participant had worked as a professor were collected. The 11 participants were invited to talk about their work using open-ended questions: (a) could you please report any teaching experience on patient safety in training settings in this university?; (b) what does patient-centered care mean to you?; (c) what are the facilitators and challenges that you face concerning patient safety teaching here?; (d) could you provide any suggestions to move forward in teaching and learning about patient safety?; (e) what is the advantage of having an IPE pedagogical project in relation to other universities/campuses in Brazil for teaching and learning about patient safety? The participants were also asked if they had anything else to add or share.

Interviews were recorded digitally and ranged in length from 15 to 48 minutes. One of the interviews was undertaken by telephone, and ten were completed face-to-face. The interviews were arranged according to the professor's availability. The face-to-face interviews were carried out during work time at each professor's office. All the interviews were individual, semi-structured, and conducted by the first author (a master's degree student trained in patient safety and IPE fields) who also prepared the interview topic guide. 
All participants had received information about the research goals and the reasons for undertaking it at the campus through their professional e-mail but were not told about the researcher's experience with patient safety training. During the interviews, the typical relationship between a professor and a master's degree student was maintained. Participants assumed the role of explaining something and telling their experiences as professors.

\section{Data Analysis}

The audio files were transcribed by the researcher who undertook the interviews and were anonymized using pseudonyms. Data were analyzed using thematic analysis following the Braun \& Clarke method (2006 and 2013). The interviews, which were transcribed verbatim, enabled the generation of data that provided meaningful insights into participants' knowledge, experience, and perceptions about how they perceived their work in an IPE environment, and how this environment might have facilitated patient safety learning by undergraduate students from the six courses. We used NVivo 12 to help manage the data and coding process. The data were initially coded by the lead author and then discussed formally with the fourth author (supervisor) who offered disagreement or concordance with the themes until an agreement was reached.

Although participants had different professional backgrounds, as shown in Table 1, the institution was built with an interprofessional logic, and so professors were integrated across various courses. For example, a professor with a physiotherapy background could be involved with the psychology course and with physical education students at the same time. Therefore, data analysis was not separated by professional groupings, although a key difference that became apparent between the groups' understanding of patient safety is reported in our findings. Depending on the year of the course, professors were arranged by groups of work rather than by professional divisions. The proposal here was to search for how an IPE experience could facilitate or hinder patient safety teaching for students rather than focusing on professional background.

\section{Ethical Considerations}

Formal ethical approval was required for this study. The project was approved by the Research Ethics Committee (CEP), CAAE 46378615.0.0000.5505 and Opinion No. 1,135,237 of 7/1/2015 following the Declaration of Helsinki. The professors who agreed to participate in the research were provided with a participant consent form before the interviews. Participants did not receive financial incentives or any other incentives to take part in this study. Participation in the study was voluntary. Once the research was concluded, all participants received a thank you message and were invited to a presentation of the findings and results by the first author.

\section{Results}

\section{Demographics}

Eleven professors participated in a one-to-one interview. Please, see demographic characteristics in Table 1. 
Table 1: Demographic Characteristics of Participants $(n=11)$.

\begin{tabular}{l|l}
\hline Characteristic & $\boldsymbol{n}$ \\
\hline Background & 2 \\
\hline Nutrition & 2 \\
\hline Physiotherapy & 1 \\
\hline Psychology & 2 \\
\hline Occupational therapy & 1 \\
\hline Social work & 2 \\
\hline Physical Education & 1 \\
\hline Medicine & \\
\hline Age & 3 \\
\hline 35 to 44 years old & 6 \\
\hline 45 to 54 years old & 2 \\
\hline 55 to 64 years old & \\
\hline Experience as a professor & 7 \\
\hline 10 to 19 years long & 3 \\
\hline 20 to 29 years long & 1 \\
\hline 30 years or more & \\
\hline
\end{tabular}

\section{Themes}

Analysis of the participants' interviews identified themes showing their perceptions and experiences of the IPE curricula, as well as challenges and benefits of working in an IPE environment for patient safety teaching. Four thematic categories emerged: (a) sustaining IPE; (b) stakeholder involvement; (c) pedagogy; and (d) team learning (Figure 1).
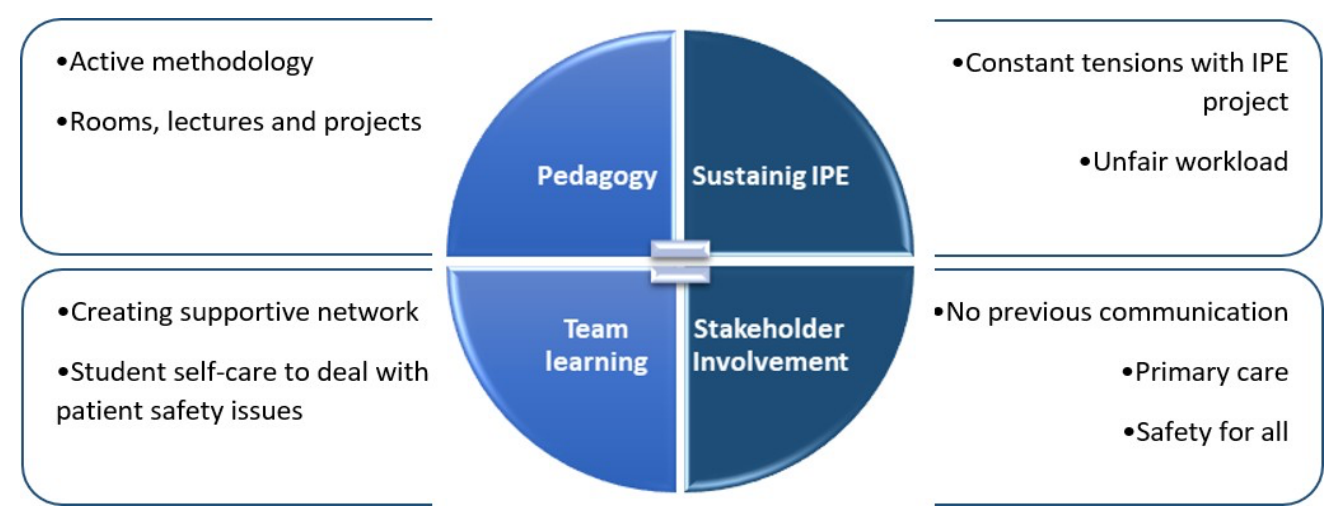

Figure 1: Thematic Categories and Sub-Themes With Facilitators (Left) and Barriers (Right). 


\section{Sustaining IPE}

All participants agreed that IPE is key to enhancing patient safety for the health system because it facilitates essential goals for teaching and learning patient-centered care, and thereby leads to improvements in health. However, maintaining an IPE project was considered a challenge. This theme consisted of the subthemes "constant tensions with IPE project" and "unfair workload." As an example of a common opinion expressed by our participants, one professor (1) noted that "not all professors here agree with the interprofessional project. It is not hegemonic, and it means that to follow this project, we feel a constant tension. Diverse opinions add an extra challenge to us" (Professor 1). Another recurrent concern is exemplified below:

I see not having an evaluation process as a weakness here, and I think that we have not instituted the evaluation of the pedagogical project at the University. I think we should have a more effective process to look at... to evaluate what works and what doesn't. (Professor 2)

Participants were concerned about the amount of time required to make sure IPE happened for their students. Considering that their career progression depends on publications, they felt that focusing time on the IPE process and associated arrangements negatively impacted their research projects and on time available to prepare papers for publication. Two participants explained:

We have an insane teaching workload... part of the period that I have with the students is there (practical training), but for me to put the students there, I have a huge logistical challenge that does not appear in my workload, and suddenly in a teaching evaluation this has no value because for being recognized as a good professor I need publications. (Professor 3)

We have a problem that escapes the University itself, which is the number of professors that should be greater. To play a pedagogical project with this degree of interprofessional goal, there must be a lot of... a lot of... interaction between people and... and... there are many more hours in the classroom that do not count for me... (Professor 2)

From the excerpts above, the professors faced difficulties when trying to operationalize their IPE project because it required a lot more interaction between professionals and time to prepare. Additional resources had not been forthcoming according to participants, which compounded these difficulties. It was also apparent that tensions could be exacerbated by different professional concerns for patient safety and their associated challenges (Figure 2). 
Vilanova et al., 2021

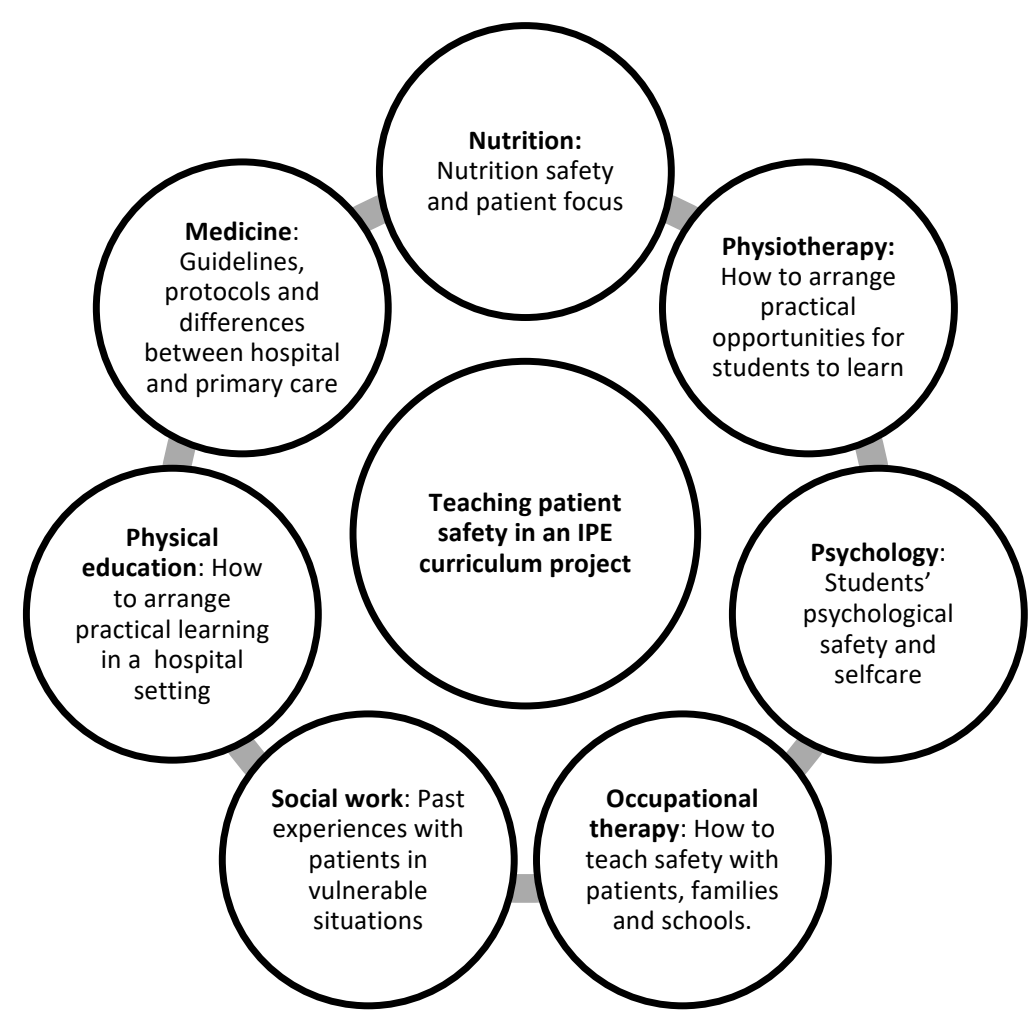

Figure 2: Interprofessional Patient Safety Concerns and Challenges

\section{Stakeholder involvement}

None of the participants had read the National Patient Safety Program (NPSP) before this research, which represents a significant barrier to patient safety teaching. Professors claimed that the program was launched without stakeholder involvement. We identified three sub-themes: "no previous communication," "primary care," and "safety for all." One participant noted that "a weakness that I see... is our lack of knowledge about the patient safety program... the government asks, but we don't know. Today for me is not knowing about this document which exists since 2013" (Professor 4). This participant was disappointed at not being advised about the national program launched in 2013. Half of the participants also pointed to concerns about differences between approaches to patient safety teaching depending on the setting. For example, one professor stated:

When you leave the hospital environment, and you go to... people who live in their homes and get sick, they have chronic problems, then the question is, how does the program consider the singularity of those people? And then it's not a patient safety protocol.... You see that it is a program mainly focused on hospital reality... in the nursing team, medical team, right? (Professor 5)

Participants were concerned that there had been a lack of discussion about the different meanings patient safety has for various levels of care inside the healthcare system. They were disappointed that these differences were not reflected in the program, as exemplified by one professor: "It (patient safety) is something transversal in any area, whether, in health, education or the social field, it turns out that it does happen all the time" (Professor 6).

The participants told us that courses from their campus worked more with the prevention and promotion of health, and that the number of professions was smaller when compared to nurses, physicians, and pharmacists who worked in hospitals. They were unsure whether the integration of nursing, medical, and 
pharmacy courses alongside their work would be better or not. However, they felt that having these professions together might increase the risk of not having an IPE project. For example, one participant noted how medical and nursing courses tended to work in silos:

We have been participating in the discussion of the need for changes in medical training, this is the difficulty... you know, right? How is training, even in nursing, how hard it is, how very specialized, fragmented it is, right? (Professor 7)

These difficulties presented a dilemma for the professors. Not having wider professional input was considered a weakness in their attempts to create a secure, well-built IPE project for a safer national healthcare system. However, they felt that medical, nursing, and pharmacy colleagues would be more resistant to working together with different professional groups, although they could add significant benefit to the IPE and patient safety initiatives.

\section{Pedagogy}

This theme is related to the facilitators of patient safety teaching from the participants' point of view. Most of them told us that using methodologies they already apply to their activities facilitated the inclusion of a new topic. Some of the teaching strategies that helped them introduce patient safety topics to their teaching routine were roleplay and interprofessional narrative construction. The subthemes in this section were "active methodology" and "rooms, lectures and projects." Participants cited some examples of methodologies that they appreciated. Half of the participants cited the use of roleplay, as one said that "in roleplay, which we sometimes do to illustrate, we do it to simulate the service, and it is quite useful for patient safety simulation." (Professor 8). However, roleplay is not a regular strategy on campus. The preferred strategy was the use of interprofessional narratives:

There are the narratives, groups and therapeutic processes that we do with two or three students from different courses. They choose a case and follow it during a whole semester together. In general, these are chronic situations where they need to discover how to deliver care and how to improve health conditions for that patient. (Professor 7)

Four participants cited narratives as an effective way to simulate practice that addressed safety topics. The narrative construction is an everyday strategy that all students do during their training. Participants described it as a well-accepted method by professors in general.

Participants also cited the use of shared rooms and how they shared lectures and projects with students from different courses. Two participants expressed their appreciation:

I don't know how the rooms were managed when this campus began in 2006, who took care of this, but it would be strange if rooms were uni-professional. Here I share with a nutritionist, an occupational therapist. That's what I breathe... for me kind of... if I had only psychologists here, I would find it strange. (Professor 9)

Students (from physical education course) are often guided and supervised by professionals from areas other than physical education. So, it is exciting interprofessional work and very close to those who will work in health, with real life. Real life in the national health system. (Professor 10)

Participants told us that some professors did have concerns about sharing a room with different professionals; however, it facilitated interprofessional projects and provided an exemplar for a project based on an IPE curriculum. Professors believed that the IPE pedagogical approach could easily embrace safety topics because they already worked with students across different courses. 
Vilanova et al., 2021

\section{Team learning}

In this final theme, professors highlighted the importance of students learning to work as a team for the benefit of patient safety. Two subthemes illustrate participants' beliefs about how to enhance patient safety teaching: "creating a supportive network" and "student self-care to deal with patient safety issues." Typical remarks were found regarding that professors "do not doubt that our students are better prepared [to work as a team] than those who do not do this process [with an IPE]." (Professor 11); or "our students learn to deal horizontally with other professions which is incredible. I don't see it in other universities" (Professor 6). The coding process revealed that more than $80 \%$ of the participants cited as an essential skill the ability to learn how to create a supportive network as an undergraduate student. Participants linked this learning with realworld practice after graduation.

To work in an interdisciplinary way is quite difficult, but... we need to create conditions for having a network, you have to build your network, and it will facilitate patient-centered care. Then, the student and the patient will benefit from a good supportive interprofessional network. (Professor 9)

Another finding was that participants often spoke of student self-care skills. They believed that during training students can learn how to cope with difficult times in their professional lives. Having a good experience at university enhanced their resilience as practicing professionals.

It is important to preserve your mental health, so I also have to look at it from the perspective of the caregiver, because if the student is dealing with a case that involves a risk, it can impact students even more if they are starting. Depending on the case, they might start questioning whether it is what they want to do... not because of disliking but because of the traumatic experience in the health care service. (Professor 9)

During and after graduation, professionals have to deal with incidents, adverse events, deaths, and near misses. So, participants from this study cited the importance of having a psychology course working alongside other courses. All professors mentioned how important it was for students to learn how to create their own supportive network, and that self-care is essential to dealing with difficult and sensitive cases during their careers.

\section{Discussion}

Analysis of the interviews provided insight into some of the key challenges and benefits the professors experienced in an IPE curriculum for patient safety teaching. The study revealed four general themes, two noted as barriers and two as facilitators. In the first theme, professors highlighted difficulties with sustaining an IPE project. Developing and implementing IPE requires commitment on the part of the university, which reflects common difficulties reported internationally, such as lack of financial support, organizational and logistical challenges, securing clinical sites, and burnout among professors (Fahs et al., 2017; Reeves et al., 2016b). Evidence suggests that the academic environment in Brazil is not unlike that of other countries.

Participants also noted tensions among professors and unfair workloads due to inadequate staffing. Some of these tensions could be attributed to the different challenges cited by professors that correlated with their professional backgrounds. For instance, the professor from a medical background talked more about guidelines and protocols than did other professors. This participant also repeatedly questioned safety differences between hospital and primary care settings. It may be that the greater responsibility doctors have for a patient's care means they are more concerned with following established treatment practices, as specified in written protocols. We might hypothesize that other professionals were more focused on prevention and were able to share their responsibilities with team members. For example, professors from a physical education background were still finding a way to be included in hospital environments. Even though 
safety is a matter of concern in all care settings, it is strongly correlated with hospital environments, and the national program highlights topics common to those settings, e.g. safe surgery and hospital-acquired infections. Other examples included occupational therapy, which focused on working with schools and families, and social work, which focused on vulnerable patients in precarious social conditions. Tensions can arise if IPE curricula do not adequately incorporate the patient safety needs of professional backgrounds. Though it is difficult to generalize from few participants of different professions, it was evident that when asked to talk about patient safety, participants did so from their own uni-professional backgrounds.

Participants were also concerned with colleagues who did not participate in the curriculum project conception in 2006 and with new professors who had no previous IPE experience. The nature of the interprofessional context in which the present study was undertaken contributes to a higher likelihood of favorable opportunities to teach patient safety. However, IPE curricula alone are not enough to achieve that goal. Tensions between staff who aligned with the IPE movement and those who preferred to work uniprofessionally might be mitigated by providing ongoing support and co-facilitation opportunities. Reeves et al. (2016b) have suggested that curricular developers keep in mind the need to help professors cope with the complex role of facilitating IPE. Our findings suggest that other efforts should be made to foster a culture that embraces interprofessional practice in addition to the provision of having a patient safety curriculum. It seems that professors were already burdened from their IPE experience. In many other countries, support to embed patient safety is used to promote interprofessional education and collaborative practice within the healthcare system (Frenk et al., 2010). In our study, the IPE pedagogical project was used to support patient safety teaching even though professors were already overloaded trying to sustain an IPE experience.

Participants affirmed that an IPE project requires additional efforts compared to their own experiences with uni-professional curricula. They had to spend more time managing classes and practical activities. This was partly because they needed to interact with other professors and think beyond their comfort zone during their practice with students. Participants viewed this negatively because it compromised their time to produce papers and publish articles. Their perceptions indicated that changes were needed in university policies and requirements, for example, better alignment of career progression with the requirements of the interprofessional project. There was no locally agreed career development framework, and professors complained about feeling pressured to find the time to research and publish while promoting IPE activities.

An equally important finding was a failure to measure the impact of IPE initiatives. Participants' views were in line with evidence that indicates IPE initiatives can improve collaborative teaching of patient safety, which in turn can positively impact the quality of care (Pronovost et al., 2016; WHO, 2010; Reeves, 2016; Fahs et al., 2017). However, the professors were concerned that their activities were not measured, and they were keen to know whether their efforts were making a difference. IPE and patient safety activities are particularly affected by practice environments where concepts and theory come up against the realities of teamwork (Cox et al., 2016). Without adequate evaluation embedded into IPE and patient safety teaching, the professors could not judge its long-term impact.

Any evaluation of IPE needs to begin with an understanding of its theoretical basis and the associated concepts that represent indicators for determining its impact. For example, Hean et al. (2012) present a range of theories that can be applied to IPE including social capital theory, from which any changes to power differentials and social inequalities would be captured to gauge its impact. Another possibility is the use of constructive alignment theory, through which learning experiences are designed as active rather than passive events. Indicators of impact would then depend on what the teaching staff wants students to be able to do as a result of the learning.

Underlying educational theories can be fleshed out with other mid-range theories that provide more concrete indicators for evaluation purposes. For example, Lee et al. (2013) propose four dimensions that any educational institution should be aware of when designing IPE curricula. The first dimension is "why," and is 
concerned with future healthcare practice needs and the reason that a curriculum is designed in a particular way. "What" is concerned with identifying sets of learning outcomes, standards, and attributes including knowledge, skills, and capabilities. The third dimension focuses on teaching, learning, and assessment strategies, and reflects the "how" of IPE. The final dimension deals with the context, local structure, and cultural aspects of "where" the curriculum is designed. These dimensions are interrelated and together provide a dynamic way to think through the design of curricula and a framework to evaluate relationships between these inputs and the attainment of outcomes.

Complementary to the dimensions proposed by Lee et al. (2013) are the six competency domains contained within the Canadian Interprofessional Health Collaborative framework (Orchard \& Bainbridge, 2016). The framework is used to map curriculum components that relate to IPE and collaborative work. It includes a selfassessment tool that captures information on role clarification, team functioning, patient- /client- /family/community-centered care, collaborative leadership, interprofessional communication, and management of interprofessional conflict. This framework can be used by teaching staff to evaluate their competences against an IPE curriculum and its intended impact.

The development of theoretical awareness and associated evaluative methodologies may be difficult among a professorial group already burdened in their "fight" to keep an IPE project alive. Indeed, Hean et al. (2012) point out that planning and delivering interprofessional education with theoretical sophistication is a challenging and time-consuming exercise. More support is needed from university administrators to make this possible, and our findings suggest that the professors would be receptive to such support, keen as they are to understand the impact of their work. The second theme indicated that professors were disappointed about not being informed of the existence of the National Patient Safety Program ([NPSP] MS, 2013). In line with the literature (Cox et al., 2016; MS, 2013; WHO, 2009, 2010, 2011), participants recommended greater alignment between education and the health system. Coordinated activities between professors, the health system, and policymakers should be encouraged to create improved conditions for productive learning environments (Cox et al., 2016). Failure to involve universities and professors more actively in the NPSP launch suggests a missed opportunity for associated campus development initiatives, especially given that the NPSP and WHO guide can be adapted to primary care and university settings (WHO, 2011; MS, 2013). Established professors could have articulated these initiatives with the local curriculum committee alongside new professors. Through the process of managing interprofessional initiatives, professors expressed a desire to share their knowledge with other colleagues. Co-location was cited as a facilitator to their interprofessional work, which promoted shared lectures and projects. Sharing a room was an excellent opportunity to enhance interprofessional behaviors. Studies have shown that both the quantity and quality of interprofessional communication and collaboration is significantly impacted by space (Oandasan et al., 2009; Lamb \& Shraiky, 2013; Brewer et al., 2017; Mckinlay et al., 2016). However, there is some dissonance within the existing literature. Being together in a room is not enough to guarantee interprofessional collaboration. A possible explanation is that participants might have low expectations related to the degree of interprofessional relations they have. Participants also revealed that some professors did not agree with shared rooms and preferred individual rooms. Simply sharing "common" places does not equate to shared thoughts and actions. Providing better room designs would allow a collective sense of co-location, but at the same time giving individuals enough personal space to work quietly when needed. A further consideration is needed about how to improve shared rooms and other spaces inside the campus to enhance professors' IPE experience. New ways of using shared rooms and other areas, including auditoriums, laboratories, and the library may be possible.

Participants were confident about being able to include safety topics in an existing curriculum but were concerned about the scope of patient safety. This is congruent with international literature that calls for different approaches regarding safety beyond merely avoiding errors and trying to find problems in the system (Sujan et al., 2019; Hollnagel, 2014). Because health is complex and includes promotion, prevention 
and rehabilitation, safety as the absence of harm is not enough to capture the many different risks within a healthcare system. Participants also cited the importance of addressing the psychological safety of professional practice. Having a psychology course integrated with other courses was seen as positive. Professors explained that psychology students were taught the concepts of self-care and therapeutic awareness, which enriched patient safety teaching with respect to burnout prevention and dealing with others' mistakes. Professors' perceptions align with findings from systematic reviews which identified that moderate to high levels of burnout are associated with poor patient safety outcomes such as medical errors (Hall et al., 2016; Garcia et al., 2019). One participant emphasized the importance of students' psychological safety when dealing with errors and knowing how to manage pressure in practice settings. The participant alluded to a team's psychological safety (TPS), which is defined as a team atmosphere that encourages individuals to feel comfortable engaging in discussion and reflection, without fear of censure (O'Leary, 2016; Appelbaum, 2020). Evidence confirms that addressing psychological safety during teaching initiatives is beneficial because it encourages students to be more open when discussing mistakes (Roussin et al., 2018).

\section{Implications for Practice and Research}

Given the burden that professors felt from their IPE experience, more support is required from university administrators to realize its potential and to allow specific subjects to flourish. There is a disconnect between requirements for career progression that many professors felt and the energy required to introduce new teaching material through interprofessional collaboration. Professors need the time and space to achieve greater integration and develop their capacity to teach patient safety in the curriculum. This would be enhanced if the university effectively communicated the NPSP and engaged more professors with its agenda. It would also be beneficial if the professors were provided time and resources to exploit IPE theory and undertake evaluations of their work. This is a missed opportunity because some professors complained that IPE work infringed on their research time. However, IPE evaluation is research work, and it would allow credit to be awarded for this activity as it might be for other research and publication endeavors.

Qualitative research would be beneficial to better understand the dynamics of how professors manage their work routine. Schot et al. (2020) also noted the importance of researching how professionals work every day to shed more light on the practice, which can lead to better learning outcomes and curriculum designs. A related recommendation by Xyrichis (2020) is to employ more observational work to generate data related to the interactive processes that occur during interprofessional activities-learning, facilitating, and collaborating-rather than relying on individuals' perceptions. The importance of psychological safety for staff highlights another fruitful area for further investigation. We also suggest that future research examine how patient safety learning may transition into improvements in practice that make a positive difference to service users and professionals.

\section{Limitations}

Notable limitations include the possibility that those who agreed to participate were those most motivated and interested in IPE and the topic of patient safety. The study was also undertaken in a particular geographical and social context by a research team embedded in the same university environment as participants. Social desirability bias may have tinted the participants' responses and the researcher's analysis of their data in unpredictable ways. However, we provide detailed contextual information so that readers can gauge the extent to which our findings are transferable to other settings and encourage future research to build on our results.

\section{Conclusion}

In this study, we sought to understand professors' experiences of an IPE curriculum regarding the inclusion and delivery of patient safety topics. Specifically, this paper explores the professors' perceptions of their 
experiences in an IPE curriculum project and how it could facilitate patient safety teaching and learning. Patient safety has been promoted at a superficial level and deeper structural changes have not followed to ensure its implementation and normalization in day-to-day academic practice. Professors revealed key challenges related to their practice that paint a complex picture of maintaining an IPE project and dealing with new national policies. New IPE initiatives have been promoted since these interviews were conducted, which have yet to be evaluated. Based on our results, we call for patient safety policy to be more integrated within the educational system. Professors may benefit from being kept informed of ongoing developments in patient safety through appropriate faculty development initiatives and being invited to support the implementation of changes in IPE curricula. Finally, while interviews revealed professors' perceptions, including barriers and facilitators to teaching patient safety within an IPE curriculum, we did not observe how this plays out in practice. This gap warrants further exploration to enable a greater understanding of the structural and process changes needed to ensure the successful integration of patient safety into undergraduate IPE curricula. 


\section{References}

Almeida, R. G. S., \& Silva, C. B. G. (2019). Interprofessional education and the advances of Brazil. Revista Latino-Americana de Enfermagem, 27, e3152. http://doi.org/10.1590/1518-8345.3148-315

Appelbaum, N. P., Lockeman, K. S., Orr, S., Huff, T. A., Hogan, C. J., Queen, B. A., \& Dow, A. W. (2020). Perceived influence of power distance, psychological safety, and team cohesion on team effectiveness. Journal of Interprofessional Care, 34(1), 20-26. http://doi.org/10.1080/13561820.2019.1633290

Batista, N. A., Rossit, R. A. S., Batista, S. H. S. D. S., Silva, C. C. B. D., Uchôa-Figueiredo, L. D. R., \& Poletto, P. R. (2018). Interprofessional health education: The experience of the Federal University of Sao Paulo, Baixada Santista campus, Santos, Brazil. Interface-Comunicação, Saúde, Educação, 22, 1705-1715. http://doi.org/10.1590/1807-57622017.069

Brandt, B., Luftiyya, M. N., King, J. A., \& Chioreso, C. (2014). A scoping exercise of interprofessional collaborative practice and education using the lens of the triple aim. Journal of Interprofessional Care, 28(5), 393-399. http://doi.org/10.3109/13561820.2014.906391

Braun, V., \& Clarke, V. (2006). Using thematic analysis in psychology. Qualitative research in psychology, 3(2), 77-101. http://doi.org/10.1191/1478088706qpo630a

Braun, V., \& Clarke, V. (2013). Successful qualitative research: A practical guide for beginners. Sage.

Brewer, M. L., Flavell, H. L., \& Jordon, J. (2017). Interprofessional team-based placements: The importance of space, place, and facilitation. Journal of Interprofessional Care, 31(4), 429-437. http://doi.org/10.1080/13561820.2017.1308318

Centre for the Advancement of Interprofessional Education (CAIPE). (2019). About CAIPE. https://www.caipe.org/about-us

Cox, M., Cuff, P., Brandt, B., Reeves, S., \& Zierler, B. (2016). Measuring the impact of interprofessional education on collaborative practice and patient outcomes. Journal of Interprofessional Care, 3O(1), 1-3. http://doi.org/10.3109/13561820.2015.1111052

Creswell, J. W., \& Creswell, J. D. (2017). Research design: Qualitative, quantitative, and mixed methods approaches. Sage.

Fahs, D. B., Honan, L., Gonzalez-Colaso, R., \& Colson, E. R. (2017). Interprofessional education development: Not for the faint of heart. Advances in Medical Education and Practice, 8, 329-336. http://doi.org/10.2147/AMEP.S133426

Farley, D., Zheng, H., Rousi, E., \& Leotsakos, A. (2015). Field test of the World Health Organization MultiProfessional Patient Safety Curriculum Guide. PLoS ONE, 1O(9), e0138510. http://doi.org/10.1371/journal.pone.0138510

Frenk, J., Chen, L., Bhutta, Z. A., Cohen J., Crisp, N., Evans, T., \& Fineberg, H. (2010). Health professionals for a new century: Transforming education to strengthen health systems in an interdependent world. The Lancet, 376(9756), 1923-58. http://doi.org/10.1016/So140-6736(10)61854-5

Garcia, C. D. L., Abreu, L. C. D., Ramos, J. L. S., Castro, C. F. D. D., Smiderle, F. R. N., Santos, J. A. D., \& Bezerra, I. M. P. (2019). Influence of burnout on patient safety: Systematic review and meta-analysis. Medicina, 55(9), 553-565. http://doi.org/10.3390/medicina55090553

Gerrish, K., \& Lacey, A. (2010). The Research Process in Nursing (6th ed). John Wiley \& Sons.

Goble, E., \& Yin, Y. (2014). Introduction to hermeneutic phenomenology: A research methodology best learned by doing it. IIQM-The Qualitative Research Blog. https://iiqm.wordpress.com/2014/10/16/introduction-to-hermeneutic-phenomenology-a-researchmethodology-best-learned-by-doing-it/ 
Vilanova et al., 2021

Gray, D. (2014). Doing Research in the Real World (3rd ed.). Sage.

Hall, L. H., Johnson, J., Watt, I., Tsipa, A., \& O’Connor, D. B. (2016). Healthcare staff wellbeing, burnout, and patient safety: A systematic review. PloS One, 11(7), e0159015.

http://doi.org/10.1371/journal.pone.0159015

Hean, S., Craddock, D., Hammick, M., \& Hammick, M. (2012). Theoretical insights into interprofessional education: AMEE Guide No. 62. Medical teacher, 34(2), e78-e101.

http://doi.org/10.3109/0142159X.2012.650740

Hean, S., O’Halloran, C., Craddock, D., Hammick, M., \& Pitt, R. (2013). Testing theory in interprofessional education: Social capital as a case study. Journal of Interprofessional Care, 27(1), 10-17. http://doi.org/10.3109/13561820.2012.737381

Henriksen K., Battles J. B., Marks E. S., \& Lewin D. I. (2005). Advances in patient safety: From research to implementation. AHRQ Publication. https://www.ncbi.nlm.nih.gov/books/NBK20523

Hollnagel, E. (2014). Safety-I and Safety-II: The past and future of safety management. Ashgate.

Lamb, G., \& Shraiky, J. (2013). Designing for competence: spaces that enhance collaboration readiness in healthcare. Journal of Interprofessional Care, 27(sup2), 14-23.

http://doi.org/10.3109/13561820.2013.791671

Lawton, R. (2018). It ain't what you do (but the way that you do it): Will safety II transform the way we do patient safety? Comment on "false dawns and new horizons in patient safety research and practice." International Journal of Health Policy and Management, 7, 659-661. http://doi.org/10.15171/ijhpm.2018.14

Lee, A. A., Steketee, C. C., Rogers, G. G., \& Moran, M. M. (2013). Towards a theoretical framework for curriculum development in health professional education. Focus on Health Professional Education, 14(3), 70-83. https://search.informit.org/doi/10.3316/informit.562904617725098

McKinlay, E., Gallagher, P., Wilson, C., Gray, L., McHugh, P., \& Pullon, S. (2016). Social learning, shared accommodation and interprofessional education: "I think those conversations that you have at the dinner table....” Journal of Interprofessional Education \& Practice, 5, 1-6. http://doi.org/10.1016/j.xjep.2016.07.001

Ministério da Saúde (MS). (2013). Portaria ${ }^{0} 529$, de $1^{0}$ de abril de 2013. Institui o Programa Nacional de Segurança do Paciente (PNSP). Diário Oficial da União. Brazil. https://bvsms.saude.gov.br/bvs/saudelegis/gm/2013/prto529 0104 2013.html

O'Leary, D. F. (2016). Exploring the importance of team psychological safety in the development of two interprofessional teams. Journal of Interprofessional Care, 30(1), 29-34. http://doi.org/10.3109/13561820.015.1072142

Oandasan, I. F., Conn, L. G., Lingard, L., Karim, A., Jakubovicz, D., Whitehead, C., \& Reeves, S. (2009). The impact of space and time on interprofessional teamwork in Canadian primary health care settings: Implications for health care reform. Primary Health Care Research \& Development, 1O(2), 151-162. http://doi.org/10.1017/S1463423609001091

Orchard, C., \& Bainbridge, L. (2016). Competent for collaborative practice: What does a collaborative practitioner look like and how does the practice context influence interprofessional education? Journal of Taibah University Medical Sciences, 11(6), 526-532. http://doi.org/10.1016/j.jtumed.2016.11.002

Parahoo, K. (2006). Nursing research: Principles, practice and issues (2nd ed). Palgrave.

Pronovost, P. J., Cleeman, J. I., Wright, D., \& Srinivasan, A. (2016). Fifteen years after To Err is Human: a success story to learn from. BMJ Quality \& Safety, 25(6), 396-399. http://dx.doi.org/10.1136/bmjqs2015-004720 
Vilanova et al., 2021

Reeves, S. (2016). Why we need interprofessional education to improve the delivery of safe and effective care. Interface-Comunicação, Saúde, Educação, 20(56), 185-197. https://doi.org/10.1590/180757622014.0092

Reeves, S., Fletcher, S., Barr, H., Birch, I., Boet, S., Davies, N., McFadyen, A., Rivera, J. \&. Kitto, S. (2016a). A BEME systematic review of the effects of interprofessional education: BEME guide no. 39. Medical Teacher, 38(7), 656-666. http://doi.org/10.3109/0142159X.2016.1173663

Reeves, S., Pelone, F., Hendry, J., Lock, N., Marshall, J., Pillay, L., \& Wood, R. (2016b). Using a metaethnographic approach to explore the nature of facilitation and teaching approaches employed in interprofessional education. Medical Teacher, 38(12), 1221-1228. http://doi.org/10.1080/0142159X.2016.1210114

Roussin, C. J., Larraz, E., Jamieson, K., \& Maestre, J. M. (2018). Psychological safety, self-efficacy, and speaking up in interprofessional health care simulation. Clinical Simulation in Nursing, 17, 38-46. http://doi.org/10.1016/j.ecns.2017.12.002

Schot, E., Tummers, L., \& Noordegraaf, M. (2020). Working on working together. A systematic review on how healthcare professionals contribute to interprofessional collaboration. Journal of Interprofessional Care, 34(3), 332-342. http://doi.org/10.1080/13561820.2019.1636007

Smith, D. (2007). Husserl. Routledge

Sujan, M. A., Furniss, D., Anderson, J., Braithwaite, J., \& Hollnagel, E. (2019). Resilient Health Care as the basis for teaching patient safety-A Safety-II critique of the World Health Organisation patient safety curriculum. Safety Science, 118, 15-21. http://doi.org/10.1016/j.ssci.2019.04.046

Van Manen, M. (2016). Phenomenology of practice: Meaning-giving methods in phenomenological research and writing. Routledge.

Walton M., Woodward H., Van Staalduinen S., Lemer C., Greves F., Noble D., Ellis B., Donaldson L., \& Barraclough B. (2010). The WHO patient safety curriculum guide for medical schools. BMJ Quality \& Safety, 19, 542-546. http://doi.org/10.1136/qshc.2009.036970

World Health Organization (WHO). (2009). WHO patient safety curriculum guide for medical schools.

World Health Organization (WHO). (2010). Framework for action on interprofessional education \& collaborative practice.

World Health Organization (WHO). (2011). Multi-professional patient safety curriculum guide.

Wu, A. W., \& Busch, I. M. (2019). Patient safety: A new basic science for professional education. GMS Journal for Medical Education, 36(2), Doc21. http://doi.org/10.3205/zma001229

Xyrichis, A. (2020). Interprofessional science: An international field of study reaching maturity. Journal of Interprofessional Care, 34(1), 1-3. http://doi.org/10.1080/13561820.202

Zipperer, L. (2016). Patient safety: Perspectives on evidence, information and knowledge transfer. Routledge.

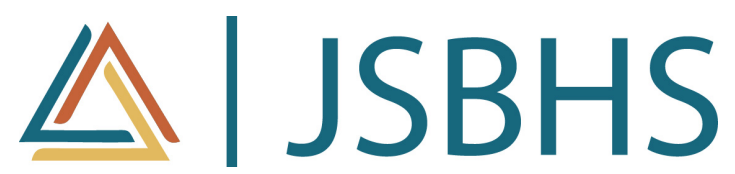

The Journal of Social, Behavioral, and Health Sciences (JSBHS), co-sponsored by the College of Health Sciences and the College of Social and Behavioral Sciences at Walden University, is a peer-reviewed, online, interdisciplinary journal focusing on theoretically-based research that addresses contemporary national and international issues. JSBHS articles include peer-reviewed research reports, brief reports, comprehensive literature reviews, book reviews, and student research. 